PSICOLOGÍA

IBEROAMERICANA
Psicología Iberoamericana ISSN: 1405-0943

revista.psicologia@ibero.mx

Universidad Iberoamericana, Ciudad de México México

\title{
La ventana, el barrio, lo político y la pandemia: autoetnografía en tiempos de covid-19
}

Ante Lezama, Minerva

La ventana, el barrio, lo político y la pandemia: autoetnografía en tiempos de covid-19

Psicología Iberoamericana, vol. 29, núm. 3, Esp., 293337, 2021

Universidad Iberoamericana, Ciudad de México, México

Disponible en: https://www.redalyc.org/articulo.oa?id=133968747008

DOl: https://doi.org/10.48102/pi.v29i3.337

\section{(c) (1)}

Esta obra está bajo una Licencia Creative Commons Atribución 4.0 Internacional 


\title{
Artículos
}

\section{La ventana, el barrio, lo político y la pandemia: autoetnografía en tiempos de covid-19}

\author{
The window, the neighborhood, the political and the \\ pandemic: Autoethnography in times of COVID-19 \\ Minerva Ante Lezama lezamamine@gmail.com \\ Universidad Nacional Autónoma de México, México \\ https://orcid.org/0000-0002-9150-281X
} Psicología Iberoamericana, vol. 29, núm.
3, Esp., 293337, 2021

Universidad Iberoamericana, Ciudad de México, México

Recepción: 02 Febrero 2021

Aprobación: 10 Junio 2021

DOI: https://doi.org/10.48102/ pi.v29i3.337

Redalyc: https://www.redalyc.org/ articulo.oa?id=133968747008

Financiamiento

Fuente: Programa de Becas Posdoctorales en la UNAM (POSDOC) 2020

No de contrato: Programa de Becas Posdoctorales en la UNAM (POSDOC) 2020

Beneficiario: Minerva Ante Lezam
Resumen: En este artículo se busca responder a la pregunta ¿cómo ha sido mi vivencia personal y en comunidad durante el encierro y cómo se relaciona con mi práctica investigativa? Narraciones personales escritas entre marzo de 2020 y enero de 2021 fueron mi fuente de información. Identifiqué cómo se enmarcan algunas experiencias personales significativas en mi contexto cultural, en términos de vivienda, vecindad y derecho a la ciudad. Relacioné dichas vivencias con problemas teóricos y prácticos relativos al habitar colectivamente la ciudad en un contexto de crisis urbana; desde la psicología social, los estudios urbanos críticos, la teoría feminista, y el Enfoque Basado en Derechos Humanos (EBDH) en las políticas públicas. Presento 2 secciones a modo de resultados: 1) Tener una ventana. 2) Estar en el barrio. Muestro cómo esos elementos son punto de partida para visibilizar aspectos cotidianos y afectivos de la vivencia, así como fenómenos macrosociales que implican desigualdades. Discuto algunas limitaciones de la auto-etnografía y concluyo enfatizando la importancia de diversificar las perspectivas en la producción de conocimiento y de rescatar la experiencia autobiográfica.

Palabras clave: Covid-19, auto-etnografía, relaciones vecinales, experiencia de barrio, derecho a la ciudad.

Abstract: I seek to answer the question: how was my personal and community experience during the confinement, and how is it related to my research practice? Personal narratives written between March 2020 and January 2021 were my source of information. I analyse how are these experiences framed in my cultural context in terms of housing, neighbourhood relations and the right to the city. I related these experiences to some theoretical and practical problems related to collectively inhabiting the city in a context of urban crisis; from social psychology, critical urban studies, feminist theory and the Human Rights-Based Approach (HRBA) in Public Policies. I present the results in two sections: 1) Having a window, and 2) Being in the neighbourhood. I show how these two elements are a starting point to make visible both the daily and affective aspects of neighbourhood life as well as the macrosocial phenomena that imply inequalities and differences. I discuss some limitations of autoethnography and conclude by highlighting the importance of diversifying perspectives in the production of knowledge and autobiographical experience.

Keywords: COVID-19, autoethnography, neighbourhood relations, neighbourhood experience, right to the city.

\section{Introducción}

Las experiencias en el habitar urbano están atravesadas por las distintas categorías sociales que encarnamos: clase, género, origen étnico, color 
de piel, lugar donde nacimos, capital cultural, social y espacial heredado y adquirido. De igual manera, son afectadas por las condiciones macrosociales de cada época y de cada geografía, por lo tanto, también se comparte una experiencia transversal.

Desde la psicología social, se ha observado la interdependencia entre mente y sociedad con todas sus implicaciones. Una ruta analítica ha sido la de la dimensión social de la identidad que, de alguna manera da pistas de esa interrelación e interdependencia entre lo micro y lo macro. La identidad social y sus posibles manifestaciones son relacionales. Hay una permeabilidad de los sistemas de ordenamiento de género o de clase, por ejemplo, en la propia construcción de la identidad a partir de la autocategorización del yo (Scandroglio et al., 2008); así mismo, es posible la afectación de dichos sistemas desde la propia agencia.

La teoría feminista ha puesto en relevancia la subjetivación psicológica y social de un sistema sociopolítico de ordenamiento y jerarquización sexo-genérica de la sociedad que se puede traducir en una condición de opresión y explotación de género (Amorós \& De Miguel, 2020; Berlanga et al., 2009; Fraser, 2020). La identidad, desde esta óptica, se ve afectada por los mandatos de género y las expectativas de roles de género, y ello deriva en relaciones y dinámicas diferenciadas.

La psique humana se construye en colectivo y la identidad está siendo constantemente afectada por los otros. Somos seres producto de los procesos de socialización que se vivencian en las distintas etapas de la vida y en los distintos sistemas en los que se interactúa. El barrio representa un espacio de expresión y construcción de la identidad. Es un espacio intermedio entre la individualidad y la sociedad en extenso; entre la vivienda en tanto espacio privado, pero también relacional, y la ciudad en tanto espacio público extendido. Gravano (2005) evidencia cómo éste ha sido abordado como objeto de estudio en las ciencias sociales al respecto de los procesos de identidad, pertenencia y sentido de comunidad.

Mayol (1999) plantea el barrio como "el espacio de una relación con el otro como ser social... un acto cultural, no arbitrario: inscribe al habitante en una red de signos sociales cuya existencia es anterior a él" (p. 11); lo concibe como una extensión del habitáculo, como una práctica cultural: "la práctica cultural del barrio". Ésta implica un orden implícito en las relaciones vecinales, la define como "una convención colectiva tácita, no escrita, sino legible para todos los usuarios a través de los códigos del lenguaje y del comportamiento; toda sumisión a estos códigos, como toda transgresión, es inmediatamente objeto de comentarios" (Mayol, 1999, p. 14).

Para el autor esta práctica implica la certeza del reconocimiento, pues en el barrio a diferencia de la ciudad, no existe el anonimato, aunque ello no implica que exista la intimidad característica de las relaciones afectivamente cercanas. En el barrio se practica "la conveniencia", que es "la gestión simbólica del rostro público de cada uno de nosotros" (Mayol, 1999, p. 15). La anterior implica tanto el pasar desapercibidos como el manifestar comportamientos estereotipados que no transgredan el orden barrial. 
La pandemia por Covid-19 entre los años 2020 y 2021, afectó de múltiples maneras los procesos del habitar y del relacionarnos en los barrios. En este análisis pretendo contribuir a comprender esos efectos desde mi propia mirada. Desde ciertos ángulos de las ciencias sociales, se ha puesto en relevancia el hecho de que producimos el conocimiento académico desde posturas hegemónicas que implican visiones masculinas y occidentales, prácticas extractivistas del conocimiento de otros y una eliminación de las emociones y de formas de percibir subjetivas y plurales (Denzin \& Lincoln, 2017; Gough et al., 2013; Kern, 2020; Navarro, 2016).

La vivencia del barrio me parece un asunto crucial a explorar desde las subjetividades femeninas, pues parece que ello ha sido una omisión en la teoría urbana y social. Desde una epistemología feminista la experiencia de las mujeres representa una fuente de conocimiento muy relevante a rescatar desde la investigación social, así mismo el volvernos sujeto y objeto de investigación toma relevancia epistemológica (Amorós \& De Miguel, 2020).

En el contexto de la pandemia por Covid-19 me vi obligada a permanecer en casa; con ello surgieron una serie de experiencias de acercamiento con mi propio barrio y grupo de vecinas y vecinos, lo cual me invitó a reflexionar en torno a mi práctica profesional. En este artículo hablo desde mi experiencia ${ }^{[1]}$, reflexionando y vinculando mi vivencia personal en el barrio en tiempos de pandemia con análisis teóricos previos y en paralelo sobre el habitar urbano y las relaciones vecinales-barriales en un contexto sociopolítico actual.

Busqué responder la pregunta ¿cómo se enmarca mi vivencia personal durante la pandemia en mi contexto cultural en términos de vivienda, relaciones vecinales y derecho a la ciudad? ¿Qué me permite observar y reflexionar tal experiencia al relacionarla con mi práctica investigativa sobre fenómenos socio-urbanos? Pretendo con ello, contribuir al desarrollo de conocimiento desde una perspectiva crítica y feminista. Busco contribuir a generar narrativas que profundicen y pluralicen el conocimiento sobre el habitar el barrio.

La autoetnografía es una metodología idónea para el objetivo de mi análisis. La autoetnografía pone en relevancia nuestra experiencia desde las categorías sociales que encarnamos y en relación con quienes nos relacionamos directa e indirectamente. "La autoetnografía que atiende a la reflexividad en las relaciones con los otros es una metodología desinteresada" (Denzin \& Lincoln, 2017, p. 1096). Nos permite explorar de forma profunda nuestro contexto cultural, pues "es un género de escritura e investigación autobiográfico que [...] conecta lo personal con lo cultural" (Ellis, 2003, p. 209 en Blanco, 2012). Da cuenta del contexto cultural en el que vivimos puesto que la cultura propia representa una red entre el self y los otros: "Los otros personal o conceptualmente están conectados con el self y frecuentemente incorporados en la autoetnografía. Miembros de la familia, amigos, colegas, y vecinos, son ejemplos de otros que están conectados personalmente." (Chang, 2016, p. 65). 
Bach (2009) defiende la experiencia como una cuestión central en la investigación social en tanto es clave para construir un relato compartido del mundo que habitamos, que no está exento de sesgos como el androcéntrico. Calderón (2021), analiza el trabajo de Ruth Behar desde la autoetnografía feminista y rescata la importancia de su trabajo al partir de la experiencia vivida como sujeto preformado y corporizado que analiza sus experiencias internas y sus emociones y las entrevera con experiencias de otros; ello posibilita la producción de nuevas prácticas epistemológicas y el romper con aquellas que dividen emoción de razón, despreciando la primera. Antivilo (2013) sostienen que el trabajar con la propia experiencia representa una narrativa empoderada que nos permite reconocer la vivencia de experiencias transversales que vivimos desde ciertas subjetividades, así como autorrepresentar nuestras propias vivencias.

La autoetnografía no se trata de escribir sobre una o uno misma solamente sino de analizar críticamente y poniendo en contexto la propia experiencia (Méndez, 2013). Implica una metodología cuidadosamente planeada, sistemática y delimitada, pero no lineal (Chang, 2016). Con ello también se pone en relevancia lo que Gago (2019) llama la experiencia situada o el pensar situado, que nos permite comprender cómo nuestro propio cuerpo y experiencias nos ensamblan desde distintas geografías con procesos globales.

Rescato y pongo en relevancia mi experiencia como fuente de información valiosa para la producción de conocimiento. Particularmente, mi experiencia como mujer migrante en la Ciudad de México (CDMX) con conciencia de género me permite visualizar mi proceso de habitar una vivienda, un barrio y una comunidad en tiempos de pandemia. Lo hago desde una subjetividad corporizada específica que contribuye a una producción de conocimiento plural. Al mismo tiempo, la dinámica vecinal vivenciada tiene cierta particularidad y transversalidad con la vida vecinal contemporánea. La apuesta metodológica planteada es intencional y atiende a una voluntad de contribuir a la producción de conocimiento desde epistemologías situadas, críticas y feministas.

\section{Método}

Realicé un análisis cualitativo autoetnográfico en donde yo misma soy sujeto y objeto de estudio. Una serie de narraciones personales escritas y algunas fotografías fueron la fuente de información. Para responder a la pregunta de investigación realicé una serie de narraciones a modo de bitácora y registros de fotografías y notas posteriores a diversas caminatas realizadas por el barrio durante los meses de confinamiento.

Seguí la apuesta "de lo específico a lo general", que, de acuerdo con Chang (2016), implica explorar la propia vivencia, en este caso en el contexto de la pandemia, y rescatar aspectos significativos que me permitieron establecer una relación con cuestiones generales del modelo y sistema cultural en el que co-existo, cuestiones con las que estoy vinculada debido a mi práctica investigativa. 
Los ejes o categorías de análisis que orientaron mi narración fueron: 1 ) Mi experiencia en la vivienda que habito en el contexto de la pandemia. 2) Mi experiencia en relación con mis vecinas y vecinos. 3) La dinámica de las relaciones que observé en el barrio.

El análisis de los datos implicó dos procesos complementarios: el zoomin y el zoom-out (Chang, 2016). El primero implica profundizar en la diversidad de datos de cada categoría de análisis. Para ello, identifiqué los hechos que consideré que fueron clave o notorios en cuanto a mi vínculo con el espacio y con las y los vecinos en tiempos de pandemia. El segundo implica relacionar los datos personales con el contexto cultural y con la teoría revisada. Para ello, me hice la pregunta ¿cómo se enmarcan dichas experiencias en mi contexto cultural en términos de vivienda, relaciones vecinales y derecho a la ciudad? Relacioné esas vivencias personales con datos diagnósticos de distinta índole y escala que conozco por experiencias investigativas previas, así como con nociones teóricas que he abordado en otros estudios o que actualmente estoy revisando como parte de mi práctica investigativa.

El texto final fue escrito en el mes de enero de 2021, después de haber estado durante 10 meses en confinamiento en un departamento de $65 \mathrm{~m} 2$ en la zona sur de la Ciudad de México haciendo teletrabajo y apegándome a las recomendaciones que el gobierno mexicano emitió en las distintas fases de la pandemia de Covid-19.

Me aseguré de guardar el anonimato de vecinas y vecinos que fueron participes de las vivencias que narro en este trabajo. No revelo información sobre ellos que pueda ser motivo de vulneración. La información personal que forma parte de este análisis no pone en riesgo mi integridad ni vulnera mi seguridad, pues representa una serie de análisis y reflexiones sobre condiciones generales que afectan nuestra experiencia de ciudad y datos públicos generados por estudios diversos. Considero este trabajo un ejercicio de honestidad, en donde expongo mi propia experiencia sobre cuestiones que suelo abordar en mi práctica como investigadora social.

Presento los resultados y discusión en dos partes. En cada apartado inicio rescatando un aspecto clave o ancla analítica en torno al tema enunciado, y a partir de ahí voy entretejiendo significados y valoraciones personales con datos diagnósticos y teóricos.

En la primera, titulada "Tener una ventana", reflexiono en torno a la ventana como puente entre la ciudad, la humanidad del espacio urbano y yo; como un dispositivo que funciona en tanto cordón umbilical con el mundo en tiempos de pandemia, como un símbolo y una materia de continuidad y conectividad social a pesar del confinamiento, y como una metáfora del derecho a la vivienda.

En la segunda, titulada "Estar en el barrio", reviso las implicaciones de la posibilidad de estar en el barrio y tener contacto con los vecinos; posibilidad que en circunstancias habituales es muy limitada dadas las condiciones de vida de las y los mexicanos al respecto de su uso del tiempo. Relaciono tal cuestión con experiencias previas de trabajo en comunidad 
en donde resultaba materialmente imposible el contacto y organización vecinales.

\section{Resultados y discusión}

"Tener una ventana": la ventana como puente entre el espacio privado y la ciudad, y como indicador socioeconómico

Una ventana que comunica a la vivienda con la calle puede ser valorada o padecida. La psicología ambiental ha teorizado sobre la habitabilidad de la vivienda, la posibilidad de contacto con el exterior se ha descrito como un factor de confort (pues se tiene control de lo que ocurre afuera) tanto como de obstáculo a la privacidad. Desde el punto de vista arquitectónico y constructivo, las ventanas representan un incremento en los costos de producción de la vivienda. En tanto símbolo, la ventana representa vínculo, conexión, contacto.

Tras analizar las condiciones de la vivienda que habité durante más de un año en confinamiento, identifiqué que el contar con una gran ventana, que me mantuvo en contacto directo y constante con la calle, resultó fundamental para sobrellevar las limitaciones de movilidad; al mismo tiempo representó la posibilidad de darme cuenta de los significados de mi experiencia de habitar esta ciudad y mi propio barrio. Durante ese tiempo la constante fue permanecer en casa, continué dando clases, asistiendo a seminarios, a reuniones con organizaciones sociales y revisando información para una investigación en curso sobre el conflicto y la cohesión barriales, todo ello "online" en mi escritorio junto a la ventana o en el comedor, muy cerca de ella.

Llegué a escribir alguna vez "la ciudad es mi casa", me concibo a mí misma como una mujer que se ha apropiado profundamente de la ciudad que habita y disfruta de su estar en ella y de transitarla. La experiencia de ciudad reducida a ir al mercado o al supermercado por los insumos alimenticios o a algunos encuentros breves con amistades, atravesados por un estado de alerta anunciado continuamente, representó para mí una rotunda novedad. En lugar del continuo movimiento con constantes salidas y entradas, apareció la quietud, el teletrabajo, la permanencia y la ventana.

La ventana se resignificó como un cordón umbilical que me mantenía conectada a la calle, al espacio público, a la ciudad en tanto casa deseada. La ventana estuvo ahí desde antes, pero la pandemia me obligó a mirar más a través de ella, o fui yo quien se obligó a sí misma a hacerlo para no perder el contacto con la vida, para no anular el vínculo afectivo que tengo con el espacio y las comunidades urbanas, con la humanidad y la naturaleza, con la calle donde vivo.

La ventana me permitía tener consciencia de la continuidad de la vida, tanto en su dimensión humana y relacional, como natural o relativa al medio ambiente.

En el primer caso, la ventana implicó un dispositivo de visualización de la actividad humana. Describiré lo que percibía. Al mirar tan cerca la 
calle, de mediano tránsito, me percataba de los transeúntes que variaban en cantidad dependiendo de la etapa de la crisis sanitaria. Me era posible escuchar, o al menos percibir, algunas conversaciones. Nunca dejé de ver alguna cuota diaria del binomio humano-perro. Percibía los microbuses con equipo de audio y diversos géneros musicales que transitan mi calle para dar vuelta en la esquina y llegar a su base; el flujo de estos no era constante pero nunca dejaron de pasar. Me percataba del camión de la basura y del barrendero de la zona, ambos con sus propios códigos para llamar la atención; también de las patrullas que de cuando en cuando se hacían visibles, dando cuenta todos ellos de la continuidad de los servicios urbanos. Me percaté de la intensidad de la demanda de servicio de entrega de comida a domicilio por parte de negocios suscritos a aplicaciones digitales (cuyo identificador son sus mochilas de color brillante), pero también de comercios locales y cercanos de insumos y materias primas (cuyos trabajadores hacen entregas en bicicleta adaptada con un guacal o reja). Me fue imposible no percibir la amplia oferta de productos y servicios que desde la informalidad muestran una distribución horaria casi orquestal: camotes, helados, elotes, compra de fierro viejo, afilador de cuchillos, obleas, mazapanes y dulces de amaranto, tamales oaxaqueños, bísquets, tortillas, churros. Percibí una, no menos amplia, oferta de performances musicales a cambio de solidaridad económica: marimba, un solo de clarinete o saxofón, orquesta ambulante, organilleros, y, en una sola ocasión, un rockero solista con su guitarra eléctrica y su amplificador. Empecé a prestar más atención a las otras ventanas, así como a los patrones de comportamiento de algunos vecinos de la acera de enfrente. En casi tres años habitando este departamento no había reconocido al hombre anciano que lleva una vida en una recámara con constantes visitas de su enfermera. Tampoco había notado a la vecina de la ventana rota que esporádicamente se asoma a mirar la calle. Identifiqué el patrón de la vecina que los fines de semana sacude enérgicamente las sábanas desde su balcón y al vecino de la casa azul de enfrente que me resultó un ser más hiperactivo de lo que yo me considero. Identifiqué al vecino que mantiene una rutina de salidas con su hijo pequeño. Empecé a notar desde la ventana ciertas prácticas diferenciadas por género: las mujeres que barren la banqueta frente a sus casas y los hombres que van a la tienda, a la fonda por la comida, o acompañan a sus hijos a dar un paseo. Empecé a percibir a parejas jóvenes que pasean a sus perros y a adultos mayores, principalmente hombres, que también lo hacen. Había actos que me recordaban que estábamos en medio de una pandemia, como las ambulancias que pasaban a toda velocidad o las y los trabajadores de la alcaldía con sus chalecos característicos que pasaban a hacer un sondeo de la condición de salud de personas en situación de vulnerabilidad. Muchas de estas prácticas representaban lo que Mayol (1999) llama "la práctica cultural del barrio", esos movimientos normales, cotidianos y parte de la cultura de barrio. Otros representaban acciones contingentes frente a la crisis doble: sanitaria y económica. La ventana representó para mí un vínculo con la presencia humana, constante y contundente, mi vínculo con esa cultura de barrio que no había sido tan clara al no "estar" en él con 
tanta obligatoriedad. Representó también una gama amplia de estímulos que desataban mi actividad emocional.

En el segundo caso, tocante a la vida natural, la ventana posibilitaba un contacto visual constante con un gran árbol justo enfrente, una jacaranda de alrededor de 12 metros de altura. En torno a tal vegetación es posible observar todo un ecosistema que, durante el confinamiento pude apreciar con mayor claridad. A distintas horas del día algunas ardillas altamente urbanizadas recorren los cables y un par de ellas saltan justo a la jacaranda para luego recorrerla en un tono agitado. Aves de al menos 3 tipos distintos emiten sus cantos y se posan en las ramas, uno de ellos intentó insistentemente hacer su nido en una luminaria de aluminio. Por las noches de modo esporádico se puede observar algún cacomixtle trepando el tronco del árbol o cruzando la calle hasta perderse tras algún portón de metal. Dado que dos vecinas han instalado un bebedero para colibríes, algunos de ellos se posan en el cable frente a mi fachada o revolotean con su estilo característico. Por las noches es posible ver alguno que otro gato reptileando entre los autos estacionados en la calle. Otros bichos pequeños traspasan los límites de mi ventana, así como las pequeñas hojas producto de la muda de la jacaranda.

En otros momentos de mi vida, siendo estudiante y contando con menos recursos económicos, llegué a habitar por tiempos cortos espacios sin ventana o con ventanas minúsculas. Tengo la certeza de que no me hubiera sido posible llevar con el mismo grado de paciencia, tranquilidad y buen ánimo estos meses de pandemia si en vez de una gran ventana hubiera tenido un muro de concreto. Tengo la hipótesis de que en tal caso hubiera experimentado más afectos negativos, emociones de soledad y tristeza.

Visto desde la teoría de la restauración psicológica que postula la psicología ambiental, probablemente, los aspectos anteriores contribuyeron en alguna medida a mi bienestar psicológico (MartínezSoto \& Montero, 2010). Los ambientes restauradores se ubican primordialmente en dos polos: el de la vida poco urbanizada y el de una urbanización de élite. No obstante, en los niveles intermedios y a escala barrial, la posibilidad de ambientes restauradores es diversa, probablemente involuntaria, cuando es voluntaria probablemente ligada al género femenino, y quizás su posibilidad más efectiva sería por mediación gubernamental.

Mi experiencia personal con respecto a mi ventana fue descrita en los párrafos anteriores, la experiencia transversal tiene que ver con el tipo de viviendas que habitamos las y los mexicanos. De lo anterior se desprende una cuestión a revisar: la ventana como elemento clave de una vivienda que puede tener características tan diversas como el poder adquisitivo lo permita, ello, ligado a las condiciones de vida diversas que posibilita una época dada.

En 2017 fui parte de un equipo que tuvo a su cargo la responsabilidad de diagnosticar para una institución pública el derecho a la vivienda en México. En aquel entonces y a partir de la Encuesta Intercensal 2015 del INEGI y otras encuestas nacionales, encontramos algunos aspectos 
clave sobre la desigualdad en el acceso a este derecho en el país. Los enuncio a continuación: 1) De las 31.5 millones de viviendas (en el Censo de 2020 se contabilizaron 35.2), el 45\% se encuentran en condición de rezago habitacional, es decir, requieren de reparaciones mayores o sus habitantes requieren de otra vivienda puesto que viven en condición de hacinamiento; en el caso de las viviendas habitadas por comunidades indígenas, la cifra asciende al 79\%. 2) La población en situación de pobreza está virtualmente excluida del mercado formal de vivienda y está poniendo en riesgo su acceso a otras necesidades básicas por satisfacer esta necesidad; aunado a ello, se identificó que la distribución de subsidios de vivienda por parte del Estado abarcaba los distintos deciles de ingresos económicos, es decir, no se estaba focalizando en la población de menores ingresos. 3) Una de cada tres viviendas no cuenta con internet y en el ámbito rural la carencia asciende al 93\% de las viviendas. 4) La región sur, comprendida por las Entidades de Chiapas, Oaxaca y Guerrero presenta los mayores problemas de hacinamiento, carencia en la calidad de los materiales y de acceso a infraestructura, en relación con otras regiones del país; lo mismo ocurre con las periferias de las zonas metropolitanas en relación con las centralidades. 5) El 16\% de las viviendas habitadas por sus propietarios no cuenta con escrituras y el $40 \%$ de las viviendas habitadas por sus arrendatarios no cuenta con un contrato. 6) Hay desigualdades de género en la titularidad de las viviendas indígenas. 7) La zona central del país y algunos otros puntos metropolitanos y turísticos, presentan los mayores niveles de conflicto vecinal y los menores de satisfacción con el vecindario (CONEVAL, 2018).

Los datos previos dan cuenta de una realidad desigual en el acceso a la vivienda digna en tanto derecho. Las condiciones de las viviendas mexicanas pueden concebirse como un indicador de la intersección de categorías sociales ligadas a la identidad como son la clase, el género, el origen étnico, el color de piel, el acceso a capital simbólico en el núcleo familiar. Ello nos puede hablar también de un sistema desigual en donde las identidades sociales encarnadas por los individuos son jerarquizadas, excluidas o favorecidas.

La posibilidad de mirar por la ventana y encontrarlo reconfortante o no, es una cuestión de clase, de origen étnico, situada en un contexto geográfico, ligada a un barrio que probablemente no se eligió y con una correspondencia entre el capital cultural y social acumulado en el contexto inmediato a la ventana. En el contexto de la pandemia, de la ventana para adentro pueden existir historias muy diversas y distantes del derecho a la vivienda, de la ventana para afuera probablemente haya una correspondencia con ello.

Una situación más aguda, es el hecho de no poder mirar por la ventana dada la imposibilidad de la garantía de una vivienda. En las semanas recientes, participé en algunas reuniones con organizaciones populares de la ciudad, que han denunciado desalojos ilegales en el contexto de la pandemia (HICAL, 2021). Escuchar los testimonios de desalojo, principalmente de mujeres y miembros de comunidades indígenas, permite ver la fragilidad de un sistema social en donde es 
posible que una crisis sanitaria represente una oportunidad de abuso y desposesión de las identidades subalternas, vulnerando el derecho a la ciudad (Lefebvre, 2017), el derecho a la vivienda y el derecho a la salud (CNDH, 2012).

Aunado a lo anterior, México es uno más de los países en donde existe gente sin vivienda -no hay alguna fuente que haya contabilizado la cantidad de personas en esta situación- y viviendas sin gente -de acuerdo con el INEGI (2020a) de los ahora 35.2 millones de viviendas, 6.1 millones están deshabitadas.

Desde el marco de derechos humanos y el EBDH en las políticas públicas, los Derechos Económicos, Sociales, Culturales y Ambientales (DESCA) son interdependientes y ocurre que, si se vulnera uno, es muy probable que se estén vulnerando los otros. Aunado a la vulneración del derecho a la vivienda en México, se puede estar visualizando la vulneración de otros derechos, ello se agudizó en el contexto de la pandemia. Menciono algunos ejemplos: 1) La salud, pues las condiciones de hacinamiento, la mala calidad de los materiales y las insuficiencias en el acceso a servicios son indicadores de vulneración tanto del derecho a la vivienda como a la salud, por los efectos nocivos sobre la misma. En situación de pandemia se potenció la peligrosidad de la vivienda precaria en términos de salud. 2) La baja disponibilidad de internet en las casas y otras deficiencias en cuanto a los espacios habitacionales y sus características pudieron representar una notable vulneración del derecho a la educación, pues hubo que mediar por las TIC's los procesos de enseñanza-aprendizaje. 3) La pérdida de empleos reportada por el INEGI (2020b) mediante su tasa crítica laboral, que aumentó en un $10.2 \%$ a nivel nacional entre el primer y el tercer trimestre de 2020, tuvo un impacto en el poder adquisitivo; así mismo en la posibilidad de pagar una renta y adquirir insumos para el mantenimiento de la vivienda; también puso en riesgo el derecho a la alimentación. 4) El medio ambiente saludable en tanto derecho, era claramente vulnerado a decir de indicadores relacionados con las emisiones de carbono o la calidad del agua, entre otros; con la crisis sanitaria se adicionó un factor más de vulneración medio ambiental que se palpó en la vida cotidiana de todas y todos: una pandemia por un virus.

De manera consonante con el EBDH, la perspectiva de interseccionalidad planteada por ciertas corrientes del feminismo denuncia la acumulación de desventajas determinadas por los sistemas sociales cuando se suman varias de las características individuales ligadas a categorías sociales. Suelen ser las mujeres, las juventudes y las comunidades indígenas o minorías étnicas o religiosas, las poblaciones que más desventajas acumulan y que ven más vulnerados sus DESCA.

Mi situación particular me llevó a observar la distancia que tengo con la situación de las comunidades más vulneradas. De igual manera me permitió observar mi posibilidad de reflexión sobre los urbano desde mi propia vivienda.

Lo que miré por la ventana durante la pandemia me permitió ser más consciente de lo que los urbanistas llaman "una escala humana" de la 
arquitectura y el urbanismo. La posibilidad de contacto con los otros aun estando en el espacio construido se pierde en la medida en que habitamos las ciudades de forma vertical en altas torres o mega bloques departamentales. En dichas viviendas se prima un alto grado de privacidad y se pasa de la propiedad privada-casa a la propiedad privada-auto para asistir a espacios con esquemas similares, evitando "estar" en la calle o con los otros.

El "tener" una ventana es una cuestión interseccional, en donde se imbrica la clase, el género, el origen étnico, el color de piel, las aspiraciones ligadas a ello; el tipo de ventana que se tiene y lo que se mira a través de ella, también.

"Estar en el barrio": la posibilidad de confinamiento y del contacto vecinal como práctica cultural y como política de barrio

Durante más de un año fui parte de un equipo que facilitaba talleres de planeación estratégica participativa para el desarrollo comunitario en barrios de la alcaldía más densamente poblada de la CDMX. La asistencia vecinal era sumamente baja a pesar de que había una valoración positiva de los talleres, un nivel de permanencia óptimo y una participación activa de quienes asistían. En alguna sesión de alguna colonia, una vecina afirmó que un actor clave en el futuro del barrio sobre el que se hacía un autodiagnóstico comunitario eran "los ausentes". Afirmó que representaban una mayoría difícil de reconocer y escuchar pero que sin duda tenían más potencial de acción y voz que la minoría ahí presente.

Una conclusión derivada de esa experiencia narrada es que, si nos alejamos del discurso más o menos generalizado de la apatía vecinal, observamos que, de manera importante, la gente no cuenta con las condiciones materiales para la participación comunitaria, sea institucional o no institucional. Las estadísticas del INEGI (2019) sobre el uso del tiempo sobrecargado en la actividad laboral y los testimonios de algunos miembros de las comunidades me permitieron confirmarlo. Aunado a ello, es posible corroborar la limitada cantidad de parques, plazas u otros espacios que posibiliten el encuentro vecinal, sea espontáneo u organizado. En ese entonces, quienes conformábamos el equipo que facilitaba los talleres, profesionales asalariadas, experimentábamos frustración al darnos cuenta de que nosotras mismas no hubiéramos podido asistir a un proceso así, de existir en nuestros barrios debido a nuestros horarios laborales.

Desde hace algunos años he estado inmersa en temas de comunidad y vecindad. Además de la experiencia de los talleres de planeación comunitaria, he sido profesora de psicología comunitaria; hice mi investigación doctoral sobre el sentido de comunidad en el barrio y algunos efectos de la gentrificación sobre el mismo; de igual manera, me vinculé con algunos movimientos vecinales. A lo largo de diez años habitando la CDMX, tuve múltiples experiencias de mudanza a distintos barrios en donde nunca permanecí más de uno o dos años, me veía a mí misma en situación de tránsito por esos lugares. Llevo casi tres años de 
habitar mi actual residencia y, si bien es el sitio de esta ciudad donde considero que me he acercado más a la noción de "echar raíz", mis hábitos no implicaban un "estar en el barrio".

Cuando se declaró por primera vez el estado de emergencia y se alentó a la ciudadanía a quedarse en casa, en marzo de 2020, tuve la posibilidad de autoconfinarme y con ello de "estar en el barrio" a tiempo completo. Ello tuvo un efecto en mi contacto y modalidad de relación con las vecinas del edificio (en su mayoría son mujeres) y en mi consciencia de ciertas formas de interrelación vecinal de la cuadra y alrededores. De entre las numerosas experiencias vividas en el barrio durante la pandemia, rescato tres que considero que han sido fundamentales en mi percepción del mundo vecinal y en mi forma de relacionarme.

\section{Primera. Robo colectivo en mi edificio}

Hacia finales del año 2020, tocaron a la puerta, yo lavaba los trastes y escuché con poca claridad cómo mi pareja después de abrir y tras escuchar una petición, respondió con una negativa y cerró. Tras enterarme de lo acontecido me sentí conmovida y salí a ver si encontraba a la mujer que había tocado. Ella vestía un traje de enfermera, cubrebocas y mostraba desesperación y urgencia en su petición, no le pude ofrecer lo que solicitaba, pero le presté 200 pesos acordando que luego me los regresaría vía una de mis vecinas. Tuve un momento de sospecha tras entregarle el billete y me dirigí inmediatamente a contactar a la vecina por WhatsApp. Acto seguido, las vecinas y vecinos de mi edificio, que teníamos un grupo de WhatsApp creado tras el último sismo, llegamos a la conclusión de que la mujer disfrazada de enfermera nos había engañado y robado colectivamente, entre todas le facilitamos, por "pura buena fe", una suma cercana a mil pesos mexicanos. Tocó a 4 de las 5 puertas de los departamentos habitados, contándonos una historia semejante; cuidó cambiar la referencia de con quién venía; nos pedía cambio de un billete; indicaba que un taxi la esperaba afuera (situación que verificamos todos desde nuestras ventanas); y hablaba con notoria desesperación apelando a nuestra solidaridad.

Tras el suceso improvisamos una reunión vecinal en la banqueta frente al edificio, portando nuestros cubrebocas y con sana distancia. Lo primero que hicimos fue llamar a la policía local y esperar su presencia mientras aclarábamos lo ocurrido. Nos asistió un oficial de policía en una patrulla y después de revictimizarnos nos dejó el número de teléfono de nuestro responsable de cuadrante. Conforme avanzaba la reunión, era evidente que la confianza en el diálogo aumentaba; por momentos nos causaba risa la situación y por momentos angustia. Discutimos las medidas que podíamos implementar, que incluían: 1) Ubicar quiénes vivimos en el edificio y aprender nuestros nombres. 2) Tener más comunicación entre nosotros y ante algún suceso semejante contactarnos inmediatamente. 3) Hacer una denuncia ciudadana digital y solicitar al vecino de la vivienda de al lado el fragmento de video en donde su cámara registró la situación. 
4) Contactar a la administradora para reparar las luces de las escaleras, fundidas al menos desde que yo empecé a vivir en el edificio.

A partir de ese hecho, la comunicación entre nosotras no sufrió un efecto importante en términos cuantitativos, pero si cualitativos: 1) Avisos en el WhatsApp de que alguien buscaba a alguna de nosotras, seguidos de agradecimientos. 2) Ofrecimientos de ponche o tarta a quien quisiera en los días navideños. 3) Mensajes informativos y alentadores entre quienes realizamos una denuncia ciudadana en la página web destinada a ello. 4) Un mayor uso de emoticones. 5) Petición de teléfonos de algún servicio local o iniciativas de mejora de los pequeños espacios comunes. El chat vecinal tomó un tono más afectivo y menos instrumental.

Considero que los sucesos desafortunados nos permitieron darnos cuenta de algunas cuestiones: 1) Somos personas solidarias, aun con desconocidos. 2) Podemos confiar en algún grado en nuestras vecinas del edificio. 3) Podemos vivir durante años rodeadas de personas de las cuáles ni siquiera sabemos el nombre sin que ello represente un problema. 4) Como colectivo con un espacio en común, no habíamos tenido la necesidad de establecer un contacto que no fuera meramente informativo hasta que tuvimos una experiencia desafortunada compartida. 5) Corroboramos que no había que temer cierto grado de contacto con cierta calidez entre cohabitantes de un edificio.

\section{Segundo. Homenaje y gratitud públicos en el barrio}

El 13 de octubre de 2020 en una salida a caminar, me encontré en la fachada de una vivienda en mi cuadra una lona en formato vertical a modo de pendón que mostraba un texto extenso escrito a mano. Estaba fechado en el mes de octubre y firmado con el nombre una mujer seguido de " $y$ muchos más":

HOMENAJE. Nosotros rendimos un comprendido y profundo homenaje a todos aquellos que han fallecido en esta guerra. A sus familiares, a quienes sufren por el miedo a contagiarse. A aquellos que, habiéndose contagiado, piensan que ya están vacunados, pero no es así. A nuestros médicos, enfermeras, afanadores y todos aquellos que, en las trincheras de sus hospitales, ambulancias, patrullas y demás, sirven y velan por nuestros enfermos aun a costa de sus vidas, su tranquilidad y la de sus familias; se siguen exponiendo. A los policías, los paramédicos, a todos los que nos brindan un servicio. Un homenaje a quienes duermen solos, a los menesterosos. A aquellos que, en medio de su desesperación, cometen suicidio. A nuestros desempleados tan desesperados. A nuestros jóvenes que piensan que no hay futuro. Gracias Dios mío por el inmenso don de nuestra fe en ti. Te pedimos por quienes no la tienen...Amén.

¡Algunos días después se me ocurrió pegar una nota adhesiva sobre la lona que decía "Suscribo!". Para mi sorpresa, unos días más adelante había otra lona al lado con un marcador permanente colgando, que a modo de encabezado enunciaba "Adoptamos el homenaje", seguido de nombres y apellidos de distintas personas. En las siguientes semanas me tomé el 
tiempo de mirar cuántas firmas nuevas suscribían el homenaje y llegué a contar 38 antes de que desapareciera la lona. Sólo uno de los nombres era seguido por información adicional, decía "falleció víctima de insumos en el hospital contagiada con COVID 19”.

$\mathrm{Al}$ iniciar el año 2021, el 8 de enero, en otra caminata por el barrio, encontré sujeta a la reja de una ventana de un callejón, otra lona con un gran corazón color lila y la siguiente leyenda:

GRACIAS, GRACIAS, GRACIAS. A las enfermeras(os). Doctoras(es). Camilleros(as). Paramédicos. A los de la limpieza hospitalaria. A todos los hospitales... (la lista continuaba con una serie de oficios y profesiones diversas) ....A TODOS ELLOS... MUCHAS GRACIAS. ¡DIOS LOS BENDIGA!

En mis 34 años de vida, entre Colima y la Ciudad de México, nunca vi algo así. Siguiendo a Mayol (1999), tales actos no encajan en las lógicas posibles en el barrio:

El sistema de la comunicación en el barrio se halla controlado en gran medida por las convenciones. El usuario, ser directamente social prendido en una red relacional pública sobre la cual no posee todo el control, está a cargo de los signos que lo convocan al orden secreto de comportarse según las exigencias de la conveniencia. Esta ocupa el lugar de la ley, una ley enunciada directamente por el conjunto social que es el barrio, del cual ninguno de los usuarios es el depositario absoluto, pero al cual todos están convidados a someterse, para hacer posible, simplemente, la vida cotidiana. El nivel simbólico es aquel donde nace la legitimación más poderosa del contrato social que, en el fondo, es la vida cotidiana (p. 21).

El homenaje y la carta de agradecimiento expuestos a la vista de todos rompían con lo que Mayol (1999) llama "conveniencia" desde el propio lugar del contrato social que implica la cotidianidad en el barrio, es decir, bajo el acuerdo de pasar desapercibido, no hacerse notar, "abolir al máximo las diferencias de los comportamientos individuales... manifestar la menor información posible" (p. 16). En términos psicosociales podría implicar el autocensurar la silencia de identidades sociales diversas al estereotipo concebido en torno a la identidad del barrio que, según Mayol (1999) consiste en ser una especie de fantasmas. ¿Será que una situación de crisis social posibilita transgresiones a la práctica cultural del barrio? Esta transgresión tenía nombre y apellido y revelaba toda la información de su origen, parecía implicar un discurso de adultos, en uno de los casos el de una mujer, en el otro es probable que también. En mi experiencia, dichos gestos provocaron un efecto importante, a partir de esos encuentros reconocí una colectividad solidaria y afectiva en mi barrio que no había notado antes.

\section{Tercero. La jardinera común}

Cuando llegué a habitar este edificio cuya fachada tiene aspecto de maqueta de cartón hecha por alguien que empieza a estudiar arquitectura, no presté mucha atención a un pequeño y descuidado rectángulo con tierra en la banqueta. Al poco tiempo empecé a notar que había una 
práctica vecinal de dejar por la mañana apiladas ahí bolsas con basura para que se las llevara el barrendero, también que, de manera recurrente aparecían heces fecales de los perros que sacan a pasear. Conforme fui encontrándome en la azotea a una de mis vecinas cada vez que iba a lavar, nuestras conversaciones se fueron dirigiendo a la jardinera.

Después de algún tiempo alguien esparció grava en la jardinera y asumimos que había sido la vecina de al lado que remodeló su casa. Durante algunos meses se dio un proceso de planeación aletargado, encuentros esporádicos (en ese entonces yo volvía tarde de trabajar) e ideas sin concretar acciones. El robo al edificio sumado al confinamiento fueron un parteaguas.

Un día al volver del mercado miré trozos de cactus en una banqueta producto de un impacto de un automóvil en un gran ejemplar de dicha planta. Tomé un par y caminé a casa con la intención de sembrarlos en la jardinera. Una vecina de una calle aledaña al observarme me preguntó si me gustaban los cactus, le conté mi motivación y decidió regalarme dos ejemplares que tenía en su jardín. En los días subsecuentes, otro vecino que me vio caminar con otro trozo de cactus, tras indagar mis intenciones, me recetó una serie de instrucciones que su jardinero le indicó para el sembrado de un esqueje. Inauguré con la siembra de esos cactus una serie de encuentros con las vecinas en la jardinera que terminaron por concretarse en una labor de jardinería compartida por vecinas de cuatro de los cinco departamentos. Un vecino del departamento restante cuestionó si esa era una práctica legal, a lo que respondimos que probablemente no lo era pero que estábamos sustituyendo al Estado en una labor para el beneficio y disfrute de todos.

Unas semanas después, una de las vecinas consiguió unos carteles de madera, yo los pinté con un dibujo de un perro y la leyenda "recoge las heces de tu mascota" y dos vecinas más las instalaron. En las distintas fases hubo algunas comunicaciones en el grupo de WhatsApp, algunas fotografías mostrando los logros y mensajes de aliento, solidaridad y gratitud de parte de vecinas de los cinco departamentos ocupados en el edificio.

Unos meses después, el vecino que nos cuestionó sobre la legalidad de la intervención a la jardinera pública sembró una planta en otra jardinera descuidada cercana a su departamento. Unas semanas más tarde, otro vecino que no habita mi edificio pero que se acercaba a charlar con quienes intervenimos la primera jardinera durante todo el proceso, sembró una planta más.

Crenson (1983 en Gravano, 2005) afirma que cuando los vecinos generan servicios públicos, por ejemplo, al organizarse para limpiar un callejón, están constituyendo relaciones políticas entre ellos; considera que las actividades barriales son esencialmente políticas, aunque mayormente no se las considere así; plantea que los barrios no son gobierno, pero promueven el asunto de gobernar. Para tal autor, el barrio puede adquirir definición e identidad no tanto por la conciencia de sus integrantes acerca de sus lazos de identidad, sino por la verificación de 
que ellos hacen al espacio y son diferentes a otros, manifiesta que existen culturas barriales que tienen un efecto en las políticas barriales.

Después de haber estudiado los procesos de urbanización de las periferias de la Ciudad de México y de otras ciudades mexicanas, no considero que en mi barrio se atisbe alguna forma de articulación altamente organizada en torno a alguna necesidad primordial. Sin embargo, observo que de manera sutil existen de facto o como posibilidad formas de mutualidad y agencia colectiva ligadas a la vida cotidiana en un barrio que no se hace notar por procesos de expulsión, de desposesión o de grandes carencias en los servicios. Bastó una acción coordinada entre dos vecinas, para contagiar la colaboración en torno a una acción por el "hacer común"

Aunado a lo anterior, observo que en este barrio son viables formas de acción colectiva ligadas a algunos de los problemas que de acuerdo con el INEGI (2020c) son los principales a nivel nacional. El 32.5 $\%$ de habitantes del país de 18 años o más reportó haber tenido enfrentamientos y conflictos en su vida cotidiana en los últimos tres meses, de ellos. El $77 \%$ de ellos reportó que fueron con sus vecinos. Los principales problemas reportados están relacionados con las responsabilidades vecinales, el estacionamiento de los vehículos y los ladridos, ataques o desechos de mascotas. En el $50 \%$ de los casos se reportó que las consecuencias fueron gritos o insultos. Una posibilidad de enfrentar tal problema público es la legal institucional. Otra posibilidad de hacerlo es la organización comunitaria que tiene como precondición el reconocimiento vecinal. La comunicación, la organización, la colaboración y la confianza vecinales, suelen ser transgresiones a la práctica cultural del barrio en muchos barrios de la CDMX.

Con las experiencias anteriores, me pregunto ¿qué tan viable es la transgresión de la práctica cultural del barrio como posibilidad de transformación social de las relaciones y de gestión de los problemas comunes? Las tres experiencias narradas implican acciones colectivas; representan manifestaciones de agencia con género predominantemente femenino, transgresiones a esa práctica cultural del barrio donde el acuerdo tácito no implica ni la solidaridad ni la acción conjunta para hacer un servicio público sino el "pasar desapercibidos" o el desconfiar de los otros.

Considero que la revisión de estas experiencias que comparto contribuye a problematizar la noción de "lo común" en el barrio. Para Navarro (2016) hay "un vacío en las investigaciones académicas sobre la existencia y re-creación de lo comunitario en las ciudades, como una forma de organizar las relaciones sociales en torno a la reproducción de la vida" (p. 14). Para la autora "éste es un asunto de suma relevancia, puesto que las estrategias comunitarias suelen estar orientadas a la resolución de la gestión cotidiana de lo social ante las cada vez más adversas condiciones para vivir dignamente en las ciudades" (Navarro, 2016, p. 14).

En las experiencias narradas, identifico una lógica opuesta al "hacer común" que es trasgredida por la posibilidad de "estar en el barrio" en tiempos de pandemia, pero también por la voluntad de algunas personas 
que apuestan por la mutualidad vecinal. Considero que la metodología posibilitó observar algunas tesituras de la vida barrial que difícilmente se hubieran captado con otras metodologías.

También considero clave discutir algunas limitaciones y cuestiones problemáticas de la autoetnografía. Es una práctica ética en sí misma porque implica una estrategia metodológica que humaniza la investigación y la vuelve más incluyente en el sentido de mostrar cómo se experiencian los fenómenos sociales (Adams et al., 2013 en Lapadat, 2017). Es también una práctica ética porque implica un ejercicio de honestidad en cuanto al sentir y pensar personales (Méndez, 2013). Ello puede implicar revelar y difundir información muy íntima y que implica un alto grado de exposición personal, pudiéndose experimentar una sensación de auto vulneración.

De igual manera, al ser la experiencia personal una subjetivación de la experiencia colectiva, la auto etnografía implica también la narración en voz propia de la experiencia de otras y otros que muchas veces son seres cercanos afectivamente; frente a ello surge el dilema de si habría que consensuar con ellas o ellos lo que se está narrando y será publicado. Surgen cuestiones como ¿con quién consensuar? ¿en qué casos? Lapadat (2017) plantea que, dado que toda identidad es relacional, la autoetnografía implica una cuestión ética sobre los otros que son parte de nuestra narración. Una pregunta relevante para hacernos es si "¿nuestra libertad de narrar nuestras propias vidas está restringida por los derechos de los demás a la privacidad?" (Couser, 2004, p. 7 en Lapadat, 2017, p. 5). En mi caso no hice un consenso con las vecinas que fueron parte de las experiencias que narro, aunque pretendo compartir con ellas el texto final y escuchar su opinión.

La auto etnografía en sus hallazgos y conclusiones no se plantea como un conocimiento universal y generalizable, sino que pone en relevancia la propia voz y experiencia vivida en el contexto de experiencias transversales. Ello es a la vez una fortaleza y una limitación. La fortaleza en el sentido de que nos ayuda a profundizar en la experiencia vivida en torno a una cuestión o problema, en la medida en que accedemos a un conjunto plural de experiencias, podemos entender la cuestión con mayor amplitud y complejidad. La limitación es que, como en la mayoría de las metodologías cualitativas, el producir dicha información requiere de mayor trabajo y tiempo. En la medida en que vamos accediendo a más experiencias vividas diversas, vamos comprendiendo mejor una cuestión. De no ser así, corremos el riesgo de explicar un fenómeno social desde una perspectiva limitada.

Ha sido criticada por considerarla autoindulgente y carente de rigor al considerar como fuente de información el Self (Lapadat, 2017). Frente a ello, autores como Holt (2003) defienden que justo esa centralidad del Self es lo que aporta información relevante, única, enriquecedora del conocimiento y es la esencia misma de la metodología. Considero que mi experiencia con este trabajo contribuye de manera valiosa a la problematización de las experiencias barriales. 
La autoetnografía nos enfrenta a la histórica discusión en las ciencias sociales sobre si hay una realidad objetiva por descubrir en los fenómenos sociales o hay representaciones diversas de la realidad, atravesadas tanto por fenómenos transversales y comunes, como por experiencias situadas particulares. En este trabajo se parte de la segunda visión. Para Ellis (2000 en Méndez, 2013), una buena autoetnografía debe ser capaz de incorporar la capacidad analítica y emocional de quien la realiza, así como de generar en los lectores preguntas relacionadas con la experiencia, la posición del autor o autora, generando un aprendizaje y provocando una interlocución. Las y los lectores podrán juzgar en qué medida se logró.

\section{Conclusiones}

A partir de este trabajo auto etnográfico, me percaté de esa desconexión previa de mi labor como investigadora de fenómenos socio-urbanos, con mi cotidianidad barrial. Considero que dicha cuestión es una constante en las ciencias sociales y en la psicología. Por un lado, está vinculado con esa obsesión por la neutralidad y objetividad científica, negando nuestros vínculos experienciales con lo que estudiamos. Por otro lado, las y los investigadores somos parte de un sistema de vida marcado por la productividad y la velocidad que, en muchas ocasiones, nos obliga a renunciar a formas de agencia y vínculos comunitarios en ámbitos como el barrial.

Considero que la propia experiencia en nuestras comunidades vecinales es una fuente de saberes muy valiosa tanto como un espacio de agencia para traducir nuestra práctica profesional en acción cotidiana y comunitaria. Difícilmente tenemos tiempo libre destinado a esa práctica cultural del barrio en tanto espacio cotidiano de las relaciones e intermedio entre la vida en el hogar y la vida en la ciudad. Difícilmente transgredimos la cultura del barrio para impulsar formas de organización y acción comunitaria que implican una posibilidad de acción política desde nuestras comunidades vecinales y para el beneficio de estas. En mi caso, ello lo posibilitó la pandemia. Por primera vez en mucho tiempo pude "estar" en el barrio, sentirlo, relacionarme con quienes lo co-habito, y sucedió que ocurrieron distintos eventos de solidaridad, confianza en los otros y expresión de sentires.

Lo que narro en este trabajo, representa un conglomerado de experiencias en clave femenina. Las distintas formas de mutualidad observadas fueron impulsadas por distintas mujeres que transgredimos esa cultura de barrio que imposibilita la expresión emocional y la organización vecinal basada en la confianza, la solidaridad y el cuidado mutuo. Desde la perspectiva de género en los estudios urbanos, el espacio barrial es un espacio masculino por excelencia en tanto espacio público, pero cuando las mujeres se expresan o se organizan en él, se generan formas de resistencia o formas transgresoras de esa práctica cultural del barrio, que es por excelencia una práctica sexista, en clave masculina.

La experiencia transversal que implica mi autoetnografía, es el contexto de vulneración común: la pandemia. Considero que hay una tensión entre 
las posibilidades materiales del reconocimiento y organización vecinales y las crisis. La crisis sanitaria que estamos viviendo debido a la pandemia por Covid-19 representa una ambivalencia entre muchas otras: la posibilidad antes inconcebible para muchos de "estar" en el barrio aunada a la carga emocional negativa vinculada a la pandemia.

En mi experiencia barrial en tiempos de pandemia, ese sentimiento adquirido de confiar en la ventana como mi vínculo con la vida, me resulta consonante con el sentimiento adquirido de confiar en la vecindad al interior de mi edificio como un vínculo con la gente con la que no he decidido estar. Las manifestaciones de solidaridad y gratitud en los carteles puestos en las fachadas de dos viviendas vecinas, posibilitó una sensación de pequeña mutualidad inexistente antes para mí. Ello no implica cambios cuantiosos en el ámbito identitario o político de las y los vecinos, pero sí la conciencia de pequeños intercambios afectivos cotidianos, desde donde se puede reconocer al otro o a la otra, que es cercana pero no elegida.

El revitalizar la jardinera común representó una posibilidad de pequeño acto político en colaboración con mis vecinas que apunta a resolver los grandes problemas de conflicto vecinal enunciados por las encuestas nacionales. Ello, en mi experiencia, sentó las bases de una reestructuración de lo político en términos de crear formas de organización por el autocuidado de la comunidad, considero que son formas alternas y no institucionales de política y que están muy ligadas a la experiencia femenina.

La cuestión de interseccionalidad en los barrios sigue siendo un asunto pendiente por explorar y considero que la etnografía y la autoetnografía son recursos metodológicos muy relevantes en dicha labor, pues posibilitan el reconocimiento de experiencias que históricamente no han sido visibles en la teoría social y que resultan complementarias a la teorización existente.

Finalmente, considero que la vida barrial puede representar un espacio de posibilidad de expresión de las identidades, un laboratorio de experimentación de la pluralidad agonística que plantea Mouffe (2000), y una plataforma de liberación cognitiva ligada a la noción del Derecho a la ciudad enunciado por Lefebvre (2017). La crisis sanitaria, por un lado, evidenció una (im)posibilidad de nuestros tiempos: "tener una ventana", mientras que, por otro, representó para muchos, una posibilidad que la crisis económico-política que vivimos niega: "estar en el barrio".

\section{Agradecimientos}

Artículo escrito bajo el auspicio del Programa de Becas Posdoctorales en la UNAM (POSDOC) 2020 y con la asesoría de la Dra. Patricia Olivera Martínez. 


\section{Referencias}

Amorós, C., \& De Miguel, A. (2020). Teoría feminista (tres tomos). Malpaso Editorial

Antivilo, J. (2013). Arte feminista latinoamericano. Rupturas de un arte politico en la producción visual [Tesis doctoral no publicada]. Universidad de Chile.

Bach, A. M. (2009). Diccionario de estudios de género y feminismos. Editorial Biblos.

Berlanga, G. M. (2009). Mujer y maquila en América Latina. En M. Berlanga, J. L. Ferreyra, F. Gargallo, N. Mogrovejo \& S. E. Nuño (Eds.), Mujer y violencia: el feminismo en la era de la globalización (pp. 68-102). Universidad Autónoma de la Ciudad de México.

Blanco, M. (2012). Autoetnografía: una forma narrativa de generación de conocimientos. Andamios, 9(19), 49-74.

Calderón, Y. (2021). La autoetnografía como inflexión y performance para la producción de saberes liminales, rebeldes y nómadas. Calle 14 Revista de Investigación en El Campo del Arte, 16(29), 16-37. https://doi.org/10.14 483/21450706.17399

Chang, H. (2016). Autoetnography as method. Routledge.

Comisión Nacional de Derechos Humanos (CNDH). (2012). Pacto internacional de derechos económicos, sociales y culturales. CNDH México. https://www.cndh.org.mx/sites/all/doc/cartillas/7_Cartilla_PI DESCyPF.pdf

Consejo Nacional de Evaluación de la Política de Desarrollo Social (CONEVAL). (2018). Estudio diagnóstico del derecho a la vivienda. https://www.coneval.org.mx/InformesPublicaciones/Paginas/ Estudio-Diagnostico-Derecho-Vivienda-2018.aspx

Denzin, N. \& Lincoln, Y. (2017). The SAGE Handbook of Qualitative Research ( $5^{\mathrm{a}}$ ed.). SAGE.

Fraser, N. (2020). Los talleres ocultos del capital. Un mapa para la izquierda. Traficantes de sueños.

Gago, M. V. (2019). La potencia feminista: o el deseo de cambiarlo todo. Traficantes de Sueños.

Gough, B., McFadden, M. \& McDonald, M. (2013). Critical Social Psychology (an introduction) ( $2^{\mathrm{a}}$ ed.). Red Globe Press.

Gravano, A. (2005). El barrio en la teoría social. Espacio Editorial.

Habitat International Coalition (HICAL). (2021). Comunicado de HIC-AL y el movimiento urbano popular del 19 de enero de 2021. https://hic-al.org/2021/01/19/mexico-denuncian-contagios-y-un -fallecimiento-por-desalojos-recientes-en-la-cdmx/

Holt, L. N. (2003). Representation, legitimation, and autoethnography: An autoethnographic writing story. International Journal of Qualitative Methods, 2(1), 18-28. https://doi/pdf/10.1177/160940690300200102

Instituto Nacional de Estadística y Geografía (INEGI). (2019). Encuesta Nacional sobre el Uso del Tiempo (ENUT) 2019. https://www.inegi.org. $\mathrm{mx} /$ programas/enut/2019/ 
Instituto Nacional de Estadística y Geografía (INEGI). (2020a). Censo Nacional de Población y Vivienda 2020. https://www.inegi.org.mx/programas/ccp $\mathrm{v} / 2020 /$

Instituto Nacional de Estadística y Geografía (INEGI). (2020b). Informe de la Encuesta Nacional de Ocupación y Empleo (ENOE) al tercer semestre de 2020. https://www.inegi.org.mx/contenidos/programas/enoe/15ymas/ doc/resultados_ciudades_enoe_2020_trim3.pdf

Instituto Nacional de Estadística y Geografía (INEGI). (2020c). Encuesta Nacional de Seguridad Pública Urbana (ENSU) 2020. https://www.ineg i.org.mx/programas/ensu/

Kern, L. (2020) Feminist city. Claiming space in a man-made world. Verso.

Lapadat, J. C. (2017). Ethics in autoethnography and collaborative autoethnography. Qualitative Inquiry, 23(8), 589-603. https://doi.org/1 $0.1177 / 1077800417704462$

Lefebvre, H. (2017). El derecho a la ciudad. Capitán Swing Libros.

Martínez-Soto, J., \& Montero, M. (2010). Percepción de cualidades restauradoras y preferencia ambiental. Revista Mexicana de Psicología, 27(2), 183-190.

Mayol, P. (1999). Primera parte. Habitar. En M. Certeau, L. Giard \& P. Mayol (Eds.), La invención de lo cotidiano 2. Habitar, Cocinar (pp. 3-150). Universidad Iberoamericana.

Méndez, M. (2013). Autoethnography as a research method: Advantages, limitations and criticisms. Colombian Applied Linguistics Journal, 15(2), 279-287.

Mouffe, C. (2000). La paradoja democrática. Gedisa.

Navarro, M. L. (2016). Hacer común contra la fragmentación en la ciudad. Experiencias de autonomia urbana. Benemérita Universidad Autónoma de Puebla.

Scandroglio, B., López, J. S., \& San José, Ma. C. (2008). La Teoría de la Identidad Social: una síntesis crítica de sus fundamentos, evidencias y controversias. Psicothema, 20(1), 80-89.

\section{Notas}

1] La autoetnografía requiere de una reflexión crítica del sitio que una ocupa en un contexto social atravesado por relaciones de poder, privilegios y desventajas, así como un vinculo estrecho entre las condiciones de vida y las categorías sociales que una encarna (Denzin \& Lincoln, 2017). Por ello, describiré una serie de características personales que influyen en mi habitar y en lo que percibo. Hablo desde un sitio que encarna la categoría mujer, de más de 30 años y menos de 40 , sin descendencia y con una relación de pareja heterosexual. No me identifico como indígena. Nací en la entidad federativa más pequeña y de menor población de México, emigré a la Ciudad de México en búsqueda de alternativas profesionales y laborales. Soy hija de profesores. Tengo estudios de posgrado. En este momento tengo ingresos seguros, suficientes para vivir sin preocupaciones económicas; no tengo la certeza de continuar así dentro de un par de meses. Mi color de piel moreno claro. Soy una mujer que se asume investigadora social con perspectiva crítica, profesora de psicología social, activista feminista y por el derecho a la ciudad. 